\section{Research on the adoption barriers of the engineering construction standards in China}

Engineering construction standards in China

\author{
School of Management, Harbin Institute of Technology, Harbin, China \\ Shoujian Zhang \\ Harbin Institute of Technology, Harbin, China, and \\ Andrew Philip King \\ Nottingham Trent University, Nottingham, UK
}

Received 6 February 2015

Revised 28 May 2015

30 July 2015

25 February 2016

29 May 2016

Accepted 13 June 2016
19 November 2015

\begin{abstract}
Purpose - The engineering construction standards in China play an important role in protecting the safety of the construction projects. They are the basic principles that standardize the construction activities and guarantee the quality of projects. However, there are many barriers that affect the adoption of the engineering construction standards. Therefore, the purpose of this paper is to investigate the barriers that challenge the adoption of the engineering construction standards in China. Design/methodology/approach - The research reveals the barriers that affect the implementation of the engineering construction standards in China through a literature review. Then this study uses factor analysis to analyze 12 indices which we get from a questionnaire to build explanations from the results. Findings - According to this paper, four main brands of uncorrelated variables are derived which are the main challenges in implementing the engineering construction standards in China: management barriers, policy barriers, knowledge barriers and market barriers. This paper gives a clear classification of the barriers that the enterprises face while adopting the engineering construction standards in China.

Originality/value - This paper makes a contribution to the understanding of the barriers that affect the adoption of the engineering construction standards in China.

Keywords China, Factor analysis, Standards adoption, The engineering construction standards Paper type Research paper

\section{Introduction}

Standards are key factors for economic and competence development. Globally, there are well over half a million published standards (Bredillet, 2003). It has been widely recognized that standards are consistently important to technological innovations, industrial productivity, and so on (Zhu et al., 2006). However, if the standards adoption cannot widely work out well, their benefits will be curtailed (Fichman and Kemerer, 1997). In order to realize the benefits of the standards, it is important to fulfill and heighten the standards adoption (Rogers, 1995). Successful adoption of standards can

(C) Wei Wang, Shoujian Zhang, Andrew King. Published by Emerald Group Publishing Limited. This article is published under the Creative Commons Attribution (CC BY 3.0) licence. Anyone may reproduce, distribute, translate and create derivative works of this article (for both commercial \& non-commercial purposes), subject to full attribution to the original publication and authors. The full terms of this licence may be seen at http://creativecommons.org/licences/by/3.0/legalcode

The research work is supported by Project of the National Twelfth-Five-year Research Program of China (2012BAJ19B00). The authors are gratefully for the research group who have given suggestions and made efforts on the subject.
\end{abstract}

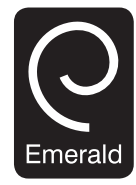

Structural Survey Vol. 34 No. $4 / 5,2016$ pp. $367-378$ Emerald Group Publishing Limited
$0263-080 \mathrm{X}$ DOI 10.1108/SS-02-2015-0010 
SS

$34,4 / 5$

368 provide enterprises with competitive advantage such as improving quality of management and achieving client satisfaction (Johnston and Vitale, 1988). Conversely, poor adoption of standards can make enterprises lose the competitive advantage (Shapiro and Varian, 1999). For example, an enterprise that adopts the green energysaving standard can meet the client's demand and earn good reputation, while the other enterprise may lose the bid or not earn the performance. The construction standards are the basic principles that standardize the construction activities and guarantee the projects' quality in China. As one of a kind of government-written standards, they provide the same function as industry-written standards in developed countries. As it has been proven that successful standards adoption has good benefits, the research on barriers in the construction standards adoption in China in this paper makes a contribution toward having a better understanding of the standards adoption. During the 2014, there were housing municipal engineering accident in more than 31 areas in China, in which, 12 areas had an increase in death accidents over the same period. These all were caused by poor implementation of the engineering construction standards. During 2014, there are more than 29 housing municipal engineering accidents, with 105 dead, which rose to respectively, 16.00 and 2.94 percent, compared to 2013.These all happened because the enterprises did not follow the engineering construction standards or adopt the standards strictly which led to the loss of people's lives and property. Take construction accidents in the Beijing Gymnasium in December 29, 2014 for example, there were ten deaths and four were injured, because the enterprises did not follow the engineering construction standards strictly when they constructed the gym.

The engineering construction standards in China play an important role in protecting people's lives and enhancing property safety in construction projects (Zhang, 2011). Research has shown that nowadays the development and adoption of engineering construction standards have affected engineering and construction in China greatly (Su and Dong, 2009). However, there are many barriers that affect the adoption of the engineering construction standards in China (Zhu and Zhang, 2011). With the development of the engineering construction, the Chinese government now has paid more attention to develop the engineering construction standards (Standard Research Institute of Housing and Urban-Rural Development of the People's Republic of China (SRIOHURD), 2014) as the construction accidents happen a lot because of the poor adoption of the engineering construction standards, and there are really lots of problem of the engineering construction standards system as China has its own standards different from the other counties and with the trend that the Chinese government pays more attention on the standardization work.

In an attempt to systemically address the adoption problems that enterprises face, the Standard Quato Department of housing and urban-rural development of the People's Republic of China (SQDOHURD) has entrusted the Standard Research Institute of housing and urban-rural development of the People's Republic of China (SRIOHURD) to undertake specific research tasks.

Research into standards has covered a variety of fields including electronic commerce (Minder, 2003), the International Accounting Standard (IAS) (Daniel and Karim, 2006; Muhammad, 2014), interorganizational systems (Chan and Chong, 2012), the institutions (Sarah and Meike, 2012) and the internet (Hovav and Patnayakuni, 2004; Hovav et al., 2011). However, there are few studies that have focused on the factors that influence the adoption of the engineering construction standards especially in China. This paper is part of the investigation of the enterprises' standardization 
status of engineering construction standards in China. The objectives of this paper are as follows:

(1) to identify the appropriate indices that impact the adoption of the engineering construction standards in China; and

(2) through the research results of this paper, give recommendations to the standard-making department - the SQDOHURD - in order to guarantee the effective implementation of the standards.

This paper's structure is as follows: second section defines and discusses the "standards" and "the engineering construction standards" in China. Third section details the methodological approach and data utilized in the study. Fourth and fifth sections outline the main results and conclusions. Finally, recommendations stemming from the work are articulated allied to the limitations of the work and areas for future enquiry.

\section{Review of challenges to engineering construction standards in China}

\section{Engineering construction standards in China}

The English word "standard" comes from Middle English and the Old French meaning rallying point (Bredillet, 2003). The Chinese word "standard" can be traced back to Qin Dynasty in $\mathrm{BC} 221$ when the government ordered to standardize the vehicle race, the written language and the coin (Tan, 1980). In this paper, we use the definition of standards in Chinese document GB/T 20000.1-2002, with a meaning of "The common use and reuse normative documents that developed by consensus and approved by a recognized body in order to obtain the optimum degree in a certain range." Worldwide, over 1,000 standard organizations have developed a huge number of standards. (Bredillet, 2003). The organizations in China that set and reformulate the standards are the SQDOHURD, the SRIOHURD and the National Standard Management Group. The SQDOHURD has published a book named An Engineering Construction Standard System (published by the China Architecture \& Building Press in 2008-05-01) in order to guide the construction work for engineering construction enterprises. In the work, the concept of the engineering construction standards in China means "The common use and reuse normative documents that developed by consensus and approved by a recognized body in order to obtain the optimum degree in the engineering and construction field range." The engineering construction standards in China have been divided into two main parts: mandatory standards and recommended standards (Yang, 2002). The mandatory standards are the standards that ensure human health, personal safety, property safety, laws and administrative regulations of compulsory execution and require compulsory adoption. On the other hand, the recommended standards are advisory and can be adopted where desired.

The adoption of standards involves numerous enterprises with differing and competing interests, some may be motivated by reputational benefits and the belief they will drive additional income, whilst others may simply see them as increasing costs. As in the Chinese engineering construction field, there are adverse phenomena such as poor implementation of standards and low adoption rate of the recommended standards, which impact construction quality, safety and energy consumption.

\section{The barriers to implementing engineering construction standards in China}

There are many barriers that hamper the adoption of the engineering construction standards in China including incomplete systems, low level of publicity, imperfect
Engineering construction standards in China 
SS

$34,4 / 5$

370

management and lack of standardization talents. The engineering construction standards can play a role only at the condition that the enterprises adopt them effectively.

However, there are a range of identified adoption issues. For example, the legal system for standards in China is problematic and lacks matching guidance documents (Zhang, 2011). Moreover, the significant amount of development in China as manifested in engineering construction and science and technology has led to a proliferation of variety of standards (Zhu and Cui, 2009). This is compounded by the lack of a unified matching approach to guide engineering construction standards (Zhu and Zhang, 2011). For example, the Standardization Law is the primary law of engineering construction standards as published in 1989 and does not tie directly to subsequently issued standards, leading to a lack of coordination between the laws and the standards, and therefore, impacts their adoption.

The engineering construction standards system in China is mainly led by the government, which controls the development of standards allied to the set up and the staff composition of the standards' technical committee. Research has shown that this leads to a disconnect between the market real demand and the engineering construction standard (Ren et al., 2007). The 12th article in the Chinese Standardization Law states that "Industry Associations, scientific research institutions and academic groups should play roles in the formulating of standards." However, in practice, nongovernmental organizations have only a very limited function.

Perhaps unsurprisingly, most operators in the enterprises engaged in the engineering construction projects pay more attention to the projects' current economic performance and ignore the standards adoption. They do not have a deep focus on the engineering construction, often neglect the publicity of the standards, disregard the standardization production process, and do not understand the standards terminology. What they do tends to depend on their past experience, and they ignores the knowledge and skills embedded in the mandatory engineering construction standards, while the recommended standards are almost abandoned. Compounding the issue is the fact that more experienced practitioners who have been engaged in the standardization process for years retire from the industry taking their knowledge with them ( $\mathrm{Mu}, 2007)$, to be replaced by the younger generation who often lack the requisite knowledge and skills and understanding of the standards.

Most enterprises agree with the opinion that the adoption of standards is a benefit for the optimization of the structure of their organizations and as a way to improve the ability to innovate (Zhu et al., 2006). However, there is a common trend in China where the Chinese enterprises are more concerned with short-term and immediate interests at the expense of long-term development. In China, most enterprises do not have an independent internal standards department, rather they combine it with other departments owing to the associated cost increase of standards adoption work or establishing the standard database.

The Chinese government conducts a selective examination method to monitor the adoption of the engineering construction standards. According to the report from the national construction engineering quality and safety supervision of law inspection, which was held in 2014 Ministry of Construction of the People's Republic of China (2004) Notice issued on printing the (Ministry of Construction of the People's Republic of China (MCC), 2004), there was 4.9 percent of enterprises in 2011 compared with 3.9 percent in 2009 and 1.9 percent in 2007 that did not meet the engineering construction mandatory standards related to various barriers in areas that interact and strengthen each other such as management, policy and market. More detailed exploration of these 
barriers will enable stronger adoption of the standards. Through the various literature articles as described above, including Zhang (2010), Zhu and Cui (2009), Ren et al. (2007), $\mathrm{Mu}$ (2007) and Zhu and Zhang (2011), we finally identified 12 indices.

\section{Methodology}

Literature was used to identify the background of the development and barriers to the successful adoption of the standards in China, resulting in the identification of 12 barrier indices. The indices were then operationalized into a questionnaire to search for the main barriers that the enterprises face.

In addition, a research group was formed in order to systematically explore the questions and barriers that the enterprises faced when adopting the engineering construction standards in China, which consisted of China Architecture Design Institute (CAG), China Institute of Building Standard Design and Research (CIBSDR), China Engineering Construction Supervision Association (CECSA), Study on comprehensive survey and Construction Design Institute Co. Ltd. (CIGIS), China Building Co. Ltd, IPPR Engineering International Co. Ltd, Beijing Wuhuan construction supervision company, and so on. Informal interviews were taken to make sure that the 12 identified barriers were directly relevant to the adoption of engineering construction standards in the Chinese environment.

A pilot study was conducted to validate the questionnaire with approximately 20 experts in the engineering construction standards. The purpose of the pilot study was to make sure the right understanding of the questions from the questionnaires and eventually determine the questionnaire.

A total of 100 survey questionnaires were sent to 100 enterprises in mainland China. The respondents from the sample were mainly standardization management personnel who had more than six years of work experience, which ensured accuracy and trustworthiness of the responses. The sample, with a 58 percent response rate, covered most provinces in China apart from the Tai Wan province.

The questionnaire had two parts. The first part related to basic information such as the type of the enterprise and the respondents' experience work years. In the second part, the respondents were asked to rate on a five-point Likert scale the 12 indices, with "least important (1)," "less important (2)," "important (3)," "quite important (4)" and "most important (5)."

\section{Data analysis}

Factor analysis uses a number of variables to describe the relationship among the clusters of the variables, or the indices, which makes it a useful statistical tool to reveal most of the raw materials' information with less factors (Carmines and Zeller, 1979). It always uses the Kaiser-Meyer-Olkin (KMO) and Bartlett's test of sphericity to test the sample's adequacy ( $\mathrm{Yu}$ and $\mathrm{He}, 2003$ ). If the KMO value is $<0.5$, it means the result effect of the factor analysis is poor (Norusis, 2008). The result of this analysis is in Table I; the KMO value in this research was 0.641 , which was higher than 0.5 , meaning

Table I.

$\mathrm{KMO}$ and Bartlett's test
Engineering construction standards in China 
SS

$34,4 / 5$

372 it was fit for factor analysis. (Li and Xin, 2008; Peter et al., 2003). The Bartlett's test of sphericity was 66 when the Sig. value was 0.000 , which suggested that the correlation matrix was not the identity matrix.

As the tests of the KMO value and the Bartlett's conformed to the inspection requirements, we then used the varimax rotation method to conduct the factor analysis (Field, 2000). Table II gives the initial and extraction communalities. Generally speaking, the conventional rule is that the extraction values are (eigenvalues) $>1$. If the extraction values (eigenvalues) are $<1$, it indicates that the explanatory factors are too weak (Kim and Mueller, 1978).

From the consequences in Table III, we identified four components whose eigenvalues were $>1.0$. The total variance cumulatively explained by the four extracted components is 71.392 percent, which is higher than the cumulative proportion of variance criterion of 60 percent (Malhotra, 1996). The four principal components, respectively, accounted for 34.622 percent, 15.797 percent, 12.068 percent and 8.905 percent.

Table IV demonstrated the results of the Rotated Component Matrix, which could improve the interpretability of the PCA results. The details of the results and the

\begin{tabular}{lcc}
\hline & Initial & Extraction \\
\hline A1: no special data archive & 1.000 & 0.687 \\
A2: lack of standardization talents & 1.000 & 0.833 \\
A3: low quality of standard operators & 1.000 & 0.746 \\
A4: no standard training & 1.000 & 0.558 \\
A5: no Standardized evaluation & 1.000 & 0.725 \\
A6: ignore the recommended standards & 1.000 & 0.630 \\
A7: imperfect standard legal system & 1.000 & 0.818 \\
A8: no standardized management department & 1.000 & 0.713 \\
A9: lack of the matching guidance document & 1.000 & 0.739 \\
A10: lack of government guidance & 1.000 & 0.792 \\
A11: nongovernmental organization do not play a role & 1.000 & 0.643 \\
A12: standard could not be made in time to fulfill the market demand & 1.000 & 0.683
\end{tabular}

Table II.

Communalities

Note: Extraction method: principal component analysis

\begin{tabular}{|c|c|c|c|c|c|c|c|c|c|}
\hline \multirow[b]{2}{*}{ Component } & \multirow[b]{2}{*}{ Total } & \multicolumn{2}{|c|}{ Initial eigenvalues } & \multicolumn{3}{|c|}{$\begin{array}{c}\text { Extraction sums of squared } \\
\text { loadings }\end{array}$} & \multicolumn{3}{|c|}{$\begin{array}{c}\text { Rotation sums of squared } \\
\text { loadings }\end{array}$} \\
\hline & & $\begin{array}{c}\% \text { of } \\
\text { variance }\end{array}$ & $\begin{array}{c}\text { Cumulative } \\
(\%)\end{array}$ & Total & $\begin{array}{c}\% \text { of } \\
\text { variance }\end{array}$ & $\begin{array}{c}\text { Cumulative } \\
(\%)\end{array}$ & Total & $\begin{array}{c}\% \text { of } \\
\text { variance }\end{array}$ & Cumulative \\
\hline 1 & 4.155 & 34.622 & 34.622 & 4.155 & 34.622 & 34.622 & 3.024 & 25.200 & 25.200 \\
\hline 2 & 1.896 & 15.797 & 50.419 & 1.896 & 15.797 & 50.419 & 2.534 & 21.117 & 46.317 \\
\hline 3 & 1.448 & 12.068 & 62.487 & 1.448 & 12.068 & 62.487 & 1.738 & 14.481 & 60.798 \\
\hline 4 & 1.069 & 8.905 & 71.392 & 1.069 & 8.905 & 71.392 & 1.271 & 10.594 & 71.392 \\
\hline 5 & 0.898 & 7.481 & 78.873 & & & & & & \\
\hline 6 & 0.637 & 5.312 & 84.185 & & & & & & \\
\hline 7 & 0.526 & 4.381 & 88.566 & & & & & & \\
\hline 8 & 0.389 & 3.243 & 91.809 & & & & & & \\
\hline 9 & 0.305 & 2.544 & 94.353 & & & & & & \\
\hline 10 & 0.278 & 2.315 & 96.668 & & & & & & \\
\hline 11 & 0.242 & 2.013 & 98.681 & & & & & & \\
\hline 12 & 0.158 & 1.319 & 100.000 & & & & & & \\
\hline
\end{tabular}




\begin{tabular}{|c|c|c|c|c|c|}
\hline & \multicolumn{4}{|c|}{ Component } & \\
\hline & 1 & 2 & 3 & 4 & construction \\
\hline A8: no standardized management department & 0.843 & -0.040 & -0.021 & -0.001 & \\
\hline A5: no standardized evaluation & 0.748 & 0.385 & 0.090 & 0.094 & \\
\hline A1: no special data archive & 0.738 & 0.134 & 0.296 & -0.192 & \\
\hline A4: no standard training & 0.701 & 0.223 & -0.130 & -0.022 & \\
\hline A6: ignore the recommended standards & 0.698 & 0.285 & 0.180 & 0.173 & נת \\
\hline A10: lack of government guidance & 0.135 & 0.875 & -0.090 & -0.001 & \\
\hline A9: lack of the matching guidance document & 0.153 & 0.830 & -0.027 & 0.162 & \\
\hline A7: imperfect standard legal system & 0.367 & 0.810 & 0.161 & -0.044 & \\
\hline A2: lack of standardization talents & -0.008 & 0.090 & 0.868 & 0.266 & \\
\hline A3: low quality of standard operators & 0.189 & -0.081 & 0.817 & -0.189 & \\
\hline A12: standard could not be made in time to fulfill the market demand & -0.063 & -0.088 & 0.217 & 0.790 & \\
\hline A11: nongovernmental organization do not play a role & -0.123 & -0.321 & 0.298 & -0.661 & \\
\hline $\begin{array}{l}\text { Notes: Extraction method: principal component analysis. Rotation } \\
\text { normalization. Rotation converged in five iterations }\end{array}$ & n metho & d: varim & lax with & Kaiser & $\begin{array}{r}\text { Rotated compor } \\
\text { ma }\end{array}$ \\
\hline
\end{tabular}

complex connections among the variables would been explained in the next stage. As a result, we divided the 12 variables into four new uncorrelated variables which can explain 71.392 percent of the total variance of the variables included in the components.

\section{Discussion of results}

From the critical examination above, the basic inherent relationship among the 12 indices was established. Based on the high factor loadings and the interrelated meanings of the indices, we grouped the indices into four categories and branded them as management barriers, government barriers, knowledge barriers and market barriers.

\section{Management barriers}

The first principal component (PC1) was composed of five indices:

(1) lack of the standard management department to be made, 0.843;

(2) ignore the recommendation standards, 0.748;

(3) no standard evaluation system, 0.738;

(4) no standard training work, 0.701; and

(5) no standard data archives, 0.698.

The PC1 accounted for 34.622 percent that can be seen in Table III. Through the understanding of the indices' meaning, we themed the PC1 without difficulty as management barriers. Choi and Chin (2001) supported the proposition that management commitment is very important to the implementation of the standards.

In China, the development of enterprise standards adoption can be viewed as relatively uneven. Many engineering construction enterprises have a tendency to pay more attention to business performance than to business management. As a result, enterprises have the problem that standards adoption is not fulfilled well, and the enterprises lack the initiative to promote standard adoption work. From the interviews with the enterprises, we found that only 24 percent enterprises had set up a discrete standard management department while 63 percent scattered their standard 
SS

$34,4 / 5$

management department among other departments. Interestingly, 13 percent of enterprises did not have a specific standard management resource. The results indicated that there is a great potential to set up discrete standards departments and additionally enhance the connection between the standards department and other departments.

\section{Policy barrier}

The second principal component (PC2) was composed of three indices:

(1) lack of government guidance to be made, 0.875 ;

(2) lack of the matching guidance document, 0.830; and

(3) imperfect standard legal system, 0.810 .

With variance contribution of 15.797 percent, the next proportion is of the $\mathrm{PC} 2$, which can be seen in Table III. We incorporated three policy barrier in this component through the understanding of the indices' meaning. This component is easy to understand as the lead of the policy is the external guide that makes the enterprises have sufficient external thrust on the standards adoption. The lack of the government's participation would hamper the adoption of the standards. Zhu and Cui (2009) point out that with the increasing number of engineering construction standards, there is a lack of matching guidance document, which has resulted in the standards having a lack of legal basis. For the development of the engineering construction standards, SQDOHURD, the Chinese government agency, now has paid more attention to the demand and barriers that the enterprises face when they use the engineering construction standards (SRIOHURD, 2014). SQDOHURD should formulate incentive measures and long-term mechanisms in addition to further developing the standards legal system to strengthen adoption.

\section{Knowledge barriers}

The third principal component (PC3) was composed of two indices:

(1) lack of standardization talents to be made, 0.868; and

(2) low quality of standard operators, 0.817.

The PC3 accounted for 12.068 percent variance that can be seen in Table III. Through the understanding of the indices' meaning, we themed the PC3 without difficulty as knowledge barriers. This component means that both knowledge and standard experts are necessary conditions for effective adoption of the engineering construction standards. As we know, professional standards talents are the basic conditions for the adoption and the supervision of the engineering construction standards. However, with the successive retirement of older generation of experts with rich experience who have been engaged in the standardization of construction for decades, there is a desperate need for large numbers of new technical staff to drive the adoption of standards in China (Mu, 2007). This is compounded by the overriding focus on current economic performance than the future society quality. As a result, it is necessary to take various effective measures to form and strengthen the construction of talents team involved in standards in various ways such as centralized training, continuing education, and taking account of older generations' experience and knowledge of standards. It is critical that the talents involved in standards ensure the smooth adoption of standards in the engineering construction work (Zhao, 2013). 
The fourth principal component (PC4) was composed of two indices:

(1) standards could not be made in time to fulfill the market demand to be made (what does this mean?), 0.790, and

(2) nongovernmental organization for standardization and industry association do not play a role, 0.661 .

The next factor is PC4 that accounted for 8.905 percent variance which can be seen in Table III. Through consideration of the indices' meaning, PC4 was themed without difficulty as market barriers. Market conditions provide significantly good environment for the adoption of the standards (Weitzel et al., 2006). However, the standards market does not function well in China owing to the way that the government plays a leading role in the standards. This has led to the disconnection between market demand and the engineering construction standards. Nongovernmental organization has a very limited role in developing and embedding standards in China. Participants involved in drawing up the standards are mostly college teachers or scholars instead of the enterprises themselves and industry association staff, leading to highly theoretical levels that lack practical significance ( $\mathrm{Li}, 2010)$. In developed countries, the enterprises and nongovernmental organizations play a crucial role in drafting the standards. If the standards are adopted, the enterprises will obtain the enormous economic benefits (Shapiro and Varian, 1999). Therefore, in order to promote the adoption of engineering construction standards in China, using the market means to create a good atmosphere for the adoption of engineering construction standards in China and cultivate the market incentive mechanism is the key point.

\section{Conclusion and recommendations}

Engineering construction standards in China represent the basic rules for preventing accidents and guaranteeing engineering quality (Zhang, 2011) and have achieved great achievements. However, their success is severely limited owing to a lack of adoption, meaning work carried out often contravenes the myriad of different standards, leading to the Chinese government paying more attention to their adoption. This paper has investigated the barriers that enterprises face when they adopt the standards. A total of 12 indices were identified from the literature review, and using principal component analysis, they were divided into four uncorrelated empirical utility of barriers of the engineering construction standards adoption: management barrier, policy barrier, knowledge barrier and market barrier. The results have helped to enhance the understanding of the barriers that enterprises face. The results will aid changes in practice including the appropriate allocation of resources and the involvement of nongovernment agencies, which will benefit in the dissemination and adoption of the standards. Although engineering construction standards are specific to China, they have the same basic meaning and function as standards in more developed countries. As adoption has great effect on the enterprises, the paper makes a contribution to the research on the barriers in the adoption of the engineering construction standards, especially in the context of China.

This study is important as it focuses on the adoption of standards in China at a time when the country sees huge development in the construction environment allied to huge advances in technology allied to a proliferation of associated standards. The findings from the result have provided some insights for the identification of barriers in 
SS

$34,4 / 5$

376

the adoption or implementation of engineering construction standards in China in both enterprise and government sectors. It has led to the formation of decisions and reliable guides for a further development and improvement on the existing environment in the China construction industry. Therefore, this may contribute to the enhancement of the adoption of the standards and make a decent environment in China's construction industry. Despite the small sample size, the analysis result had been warranted by the relevant preliminary tests associated. Also, like the other questionnaire survey researches, it was inevitably that the data were subjective as they came from the respondents' experience and perceptions; thus, a modified method may be used in the future study. Future research needs to explore the barriers that affect the adoption and implementation of the engineering construction standards in other countries and on other aspects of standards.

\section{References}

Bredillet, C.N. (2003), "Genesis and role of standards, theoretical foundations and socioeconomical model for the construction and use of standards", International Journal of Project Management, Vol. 21 No. 6, pp. 463-70.

Carmines, E.G. and Zeller, R.A. (1979), Reliability and Validity Assessment, Sage Publication, Newbury Park, CA.

Chan, F.T.S. and Chong, A.Y.L. (2012), "A SEM - neural network approach for understanding determinants of interorganizational system standard adoption and performances", Decision Support Systems, Vol. 54 No. 1, pp. 621-630.

Choi, T.W. and Chin, K.S. (2001), "A study of ISO9000 implementation and quality management practices in Hong Kong Construction industry”, Asian Journal on Quality, Vol. 2 No. 2 , pp. 1-23.

Daniel, Z. and Karim, M. (2006), "An analysis of the factors affecting the adoption of international accounting standards by developing countries", The International Journal of Accounting, Vol. 41 No. 4, pp. 373-386.

Fichman, R.G. and Kemerer, C. (1997), "The assimilation of software process innovation: an organizational learning perspective”, Management Science, Vol. 43 No. 10, pp. 1345-1363.

Field, A. (2000), Discovering Statistics Using SPSS for Windows: Advance Techniques for the Begineer, Sage Publication, CA.

Hovav, A. and Patnayakuni, R.D. (2004), "Schuff a model of internet standards adoption: the case of IPv6”, Information Systems Journal (ISJ), Vol. 14 No. 3, pp. 265-294.

Hovav, A., Hemmert, M. and Kim, Y.J. (2011), "Determinants of internet standards adoption: the case of South Korea”, Research Policy, Vol. 40 No. 2, pp. 253-262.

Johnston, H.R. and Vitale, M.R. (1988), "Creating competitive advantage with interorganizational systems”, MIS Quarterly, Vol. 12 No. 2, pp. 153-165.

Kim, J.O. and Mueller, C.W. (1978), "Factor analysis: statistical methods and practical issues", Sage University Paper Series on Quantitative Applications in the Social Sciences, Sage Publication, Newbury Park, CA.

Li, C. and Xin, L. (2008), "Study on evaluation method of reliability and validity of the questionnaire”, China Health Statistics, Vol. 25 No. 5, pp. 541-543.

Li, H. (2010), "Analysis and suggestion on the existing problems of the engineering construction standard system of China”, Construction Technology, Vol. 7, pp. 659-662.

Malhotra, N.K. (1996), Marketing Research: An Apply Orientation, 2nd ed., Prentice-Hall, Upper Saddle River, NJ. 
Minder, C. (2003), "Factors affecting the adoption and diffusion of XML and web services standards for E-business systems", International Journal of Human-Computer Studies, Vol. 58 No. 3, pp. 259-279.

Ministry of Construction of the People's Republic of China (MCC) (2004), "Management regulations of local engineering construction standardization", Standardization Work, Vol. 3, pp. 11-12, Notice issued on printing the (MCC).

$\mathrm{Mu}$, X.C. (2007), "The special structure of the status quo and countermeasures of the engineering construction standards in China”, The Special Structure, Vol. 24 No. 3, pp. 106-109.

Muhammad, A.I. (2014), "Determinants of accounting choice of noncurrent assets at IFRS first adoption among Nigerian firms", Procedia - Social and Behavioral Sciences, Vol. 164 No. 31, pp. 378-383.

Norusis, M.J. (2008), SPSS 16.0 Statistical Procedures Companion, 2nd ed., Prentice Hall, NJ.

Peter, M.A., Lackey, N.R. and Sullivan, J.J. (2003), Making Sense of Factor Analysis: The Use of Factor Analysis for Instrument Development in Health Care Research, Sage Publication, Thousand Oaks, CA.

Ren et al, (1999), “Analysis on law problems of Chinese standards”, World Standardization \& Quality Management, Vol. 3, pp. 10-13.

Rogers, E.M. (1995), Diffusion of Innovations, 4th ed., Free Press, New York, NY.

Sarah, K. and Meike, W. (2012), "New institutional arrangements and standard adoption: evidence from small-scale fruit and vegetable farmers in Thailand", Food Policy, Vol. 37 No. 37, pp. 452-462.

Shapiro, C. and Varian, H. (1999), "The art of standards wars", California Management Review, Vol. 41 No. 2, pp. 8-32.

Standard Research Institute of housing and urban-rural development of the People's Republic of China (SRIOHURD) (2014), "Notice about carrying out investigation on the status of engineering construction enterprises standardization", available at: www.ccsn.cn (accessed 2 September 2014).

Su, Y.K. and Dong, S.H. (2009), "The analysis of China's engineering construction standards' impact on the enterprise", ICCIT 2009 - 4th International Conference on Computer Sciences and Convergence Information Technology, pp. 1377-1382.

Tan, S.B. (1980), "New evaluation of Shin Shi Kyoutei's policy for 'standardize the vehicle race and the written language'", Journal of Sun Yat-sen University (Philosophy and Social Science Edition), Vol. 4 No. 4, pp. 48-56.

Weitzel, T., Beimborn, D. and Konig, W. (2006), "A unified economic model of standard diffusion: the impact of standardization cost, network effects, and network topology", MIS Quarter, Vol. 30 No. 1, pp. 489-514.

Yang, J.F. (2002), The Practical Knowledge Quiz for Engineering Construction Standards, Chinese Planning Press, Beijing, p. 49.

Yu, J.Y. and He, J.H. (2003), Data Statistical Analysis and the SPSS Application, Post \& Telecom Press, Beijing, p. 372.

Zhang, S.J. (2010), "Analysis on factors influencing standard informationization based on ISM", Journal of Harbin Institute of Technology, Vol. 239 No. 17, pp. 1692-1700.

Zhang, S.J. (2011), "Analysis on the evolution of adoption behavior of engineering construction standards”, China Civil Engineering Journal, Vol. 5 No. 5, pp. 144-148.

Zhao, H.J. (2013), "The analysis of the function and status of Guangdong province local standards in the engineering construction standard", dissertation Submitted for the Degree of Master, South China University of Technology, p. 64.
Engineering construction standards in China 
$\mathrm{SS}$

$34,4 / 5$

378
Zhu, H.l. and Cui, J.J. (2009), "Study on the relationship between engineering construction standards and laws of interaction", Science \& Technology Progress and Policy, Vol. 26 No. 21, pp. 99-102.

Zhu, H.L. and Zhang, J. (2011), "Analysis of the current situation of the engineering construction standards and its management system in China", The Standard Science, Vol. 6 No. 1, pp. 10-14.

Zhu, K., Kraemer, K.L., Gurbaxani, V. and Xu, S.X. (2006), "Migration to open standard interorganizational systems: network effects, switching costs, and path dependency", MIS Quarter, Vol. 30 No. 30, pp. 515-39.

\section{Further reading}

International Organization for Standardization (1996), International Electrotechnical Commission (ISO/IEC) Guide 2, ISO Press, Geneva.

Zheng, X.Y., Zhang, Y.G. and Whalley, J. (2013), "Monetary theory and policy from a Chinese historical perspective”, China Economic Review, Vol. 9 No. 26, pp. 89-104.

\section{Corresponding author}

Wei Wang can be contacted at: vickywings@outlook.com 